\title{
Esansiyel Tremor Tanılı Çocuk ve Ergenlerin Demografik, Klinik ve Tedavi Özellikleri: Geriye Dönük Kesitsel Bir Analiz
}

\author{
Demographics, Clinical and Treatment Characteristics of Children \\ and Adolescents with Essential Tremor: A Retrospective Cross- \\ Sectional Analysis
}

ArzU YILMAZ

Ankara Eğitim Araştırma Hastanesi, Çocuk Nörolojisi Bölümü, Ankara, Türkiye

\section{Öz}

Amaç: Çocukluk çağında gözlenen tremorların büyük kısmını esansiyel tremor (ET) oluşturmaktadır. Bu çalışmada bir eğitim araştırma hastanesinin çocuk nöroloji polikliniğince esansiyel tremor tanısı konulan olguların demografik özellikler açısından geriye dönük bilgileri analiz edildi.

Gereç ve Yöntemler: Haziran 2016-Haziran 2019 yılları arasındaki 3 yıllık süre içinde çocuk nöroloji polikliniğine titreme şikâyeti ile başvuran olgulardan esansiyel tremor tanısı Hareket Bozuklukları Derneği (1998) tanı ölçütleri esas alınarak konulan olgular incelendi. SPSS 17.0 programı analizde kullanıldı. $\mathrm{p}<.05$ anlamlıık düzeyi olarak kabul edildi.

Bulgular: Belirtilen süre içinde esansiyel tremor tanılı olguların toplam 93 olduğu, yaş ortanca değerinin 16 yıl (6-18 yaş) olduğu, \% 54.8'inin ( $n=51$ ) kız ve \% 45.2'sinin ( $n=42)$ erkek olduğu saptandı. Olguların \% 7.5 'i $(n=7)$ çocuk yaș grubunda (6-11 yaş) iken \% 92.5'i ( $n=86$ ) ergen yaş grubunda (12-18 yaş)'di. Olguların \%17.2'sinde ( $n=16)$ esansiyel tremora sekonder gelişen psikiyatrik semptomlar nedeniyle çocuk-ergen psikiyatrisine danışıldığı saptandı. Olguların \%11.8'ine ( $n=11$ ) dideral tedavisi önerildiği gözlendi. Çocuk yaş grubuna dideral tedavisi önerilmediği, çocuk ve ergen yaş gruplarının benzer oranlarda çocuk psikiyatrisi bölümüne yönlendirildiği saptandı (p>.05).

Sonuç: Esansiyel tremor benzer oranlarda kız ve erkek cinsiyetini etkilemekte ve dideral özellikle ergen grubunda tedavi seçeneği olarak gözlenmektedir. Kesitimizde hem kı-erkek cinsiyetlerinde, hem de çocuk-ergen yaş gruplarında benzer oranlarda psikiyatrik etkilenim olduğu gözlenmiştir. Bulgular literatür ile uyumludur.

Anahtar Sözcükler: Çocuk, Ergen, Esansiyel tremor, Propranolol

\section{ABSTRACT}

Objective: Most of the tremors observed in childhood constitute essential tremor (ET). In this study, retrospective information of thepatients who were diagnosed with essential tremor by the pediatric neurology out patient clinic of an education and research hospital were analyzed.

Material and Methods: Patients who were admitted to the pediatric neurology out patient clinic with a complaint of tremor in the 3-year period between June 2016 and June 2019 were diagnosed based on the criteria of Movement Disorders Society (1998). SPSS 17.0 program was used in the analysis and $p<.05$ was accepted as the level of significance.

Results: It was determined that the cases diagnosed with essential tremor were 93 in total, the median age was 16 years (6-18 years), 54.8\% ( $n=51)$ were girls and $45.2 \%(n=42)$ were boys. While $7.5 \%(n=7)$ of the cases were in the child age group (6-11 years), $92.5 \%(n=86)$ were in the adolescent age group (12-18 years). It was found that

(1)

YILMAZ A : :0000-0003-2550-9324
Çıkar Çatıșması / Conflict of Interest: Tüm yazarlar adına, sorumlu yazar çıkar çatıșması olmadığını belirtir.

Etik Kurul Onayı / Ethics Committee Approval: Bu çalıșmada ulusal ve uluslararası etik kurallara uyulmuştur. Çalışma için Ankara Eğitim ve Araștıma Hastanesi, Klinik Araștırmalar Etik Kurulu'ndan 21.04.2020-245 karar numarası ile onay alınmıștır.

Yazarların katkısı / Contribution of the Authors: YILMAZ A: Araştırma ve/veya makalenin hipotezini veya fikrini oluşturan, Sonuçlara ulașmak için planlama/ metodoloji belirleme, Araştırma/çalışmanın sorumluluğunu üstlenmek, ilerlemenin seyrini denetlemek, Hasta takibinde sorumluluk almak, ilgili biyolojik malzemelerin toplanması, veri yönetimi ve raporlama, deneylerin yürütülmesi, Sonuçların mantıksal olarak Yorumlanması ve sonuçlandırılması, Çalıșma için gerekli literatür taramasında sorumluluk almak, Çalışmanın bütününün veya önemli bölümlerinin yazımında sorumluluk almak, Yazım ve dilbilgisi dışında bilimsel olarak gönderilmeden önce makaleyi gözden geçirme.

Atıf yazım şekli / How to cite : Yılmaz A. Esansiyel Tremor Tanılı Çocuk ve Ergenlerin Demografik, Klinik ve Tedavi Özellikleri: Geriye Dönük Kesitsel Bir Analiz. Türkiye Çocuk Hast Derg 2022;16:1-4
Yazışma Adresi / Correspondence Address:

\section{Arzu YILMAZ}

Ankara Eğitim Araștırma Hastanesi, Çocuk Nörolojisi Bölümü, Ankara, Türkiye

E-posta: arzuotken@yahoo.com
Geliş tarihi / Received : 10.11.2020 Kabul tarihi / Accepted : 15.12 .2020 Elektronik yayın tarihi : 12.03 .2021 Online published

DOI: 10.12956/tchd.824209 
child-adolescent psychiatry was consulted due to psychiatric symptoms developing secondary to essential tremor in $17.2 \%(\mathrm{n}=16)$ of the cases. It was observed that $11.8 \%(n=11)$ of th cases were prescribed dideral treatment. It was found that dideral treatment was not recommended for the childage group, and the child and adolescent age groups were directed to the child psychiatry department at simila rates ( $p>$.05).

Conclusion: Essential tremor affects the gender of girls and boys in similar proportions and dideral is observed as a treatment option especially in adolescent group. In our cross-section, it was observed that there was a similar rate of psychiatric influences in both male and females exes and child-adolescent age groups. The findings are consistent with the literature.

Key Words: Child, Adolescent, Essential tremor, Propranolol

\section{GiRiş}

Tremor vücut bölümlerindeki antagonist kasların istemsiz ve ritmik bir șekilde kasılması sonucu gelișen bir hareket bozukluğudur. Çocukluk çağında tremor gözlenme sıklığı \%520 oranlarına varan bir aralıkta bildirilmiş olup tek başına bir semptom olarak ortaya çıkabileceği gibi diğer nörolojik veya sistemik bozuklukların bir semptomu olarak da gözlenebilir (1, 2).

Esansiyel tremor (ET), tremor türleri içindeki en sık görülen hareket bozukluğudur. Patofizyolojisi tam olarak bilinmeyen bozukluk baskın ve poligenik nitelikte bir kalıtımsal özellik göstermektedir (3). Etkilenen bireylerin \%50-70'inde aile öyküsü vardır. Görülme sıklığı yaşla birlikte artan bozukluk, her iki cinsiyeti de eşit derecede etkilemektedir. Yaşın artmasıyla birlikte ET insidans ve prevalansının arttığını gösterilmiştir $(4,5)$.

ET'nin karakteristik bulgusu altta yatan başka bir nörolojik bulgu ya da bozukluk olmaksızın özellikle ellerde görülen postural ve/veya kinetik nitelikteki titremelerdir. Hareket Bozukluğu Derneği'nin Tremor Araştırma Grubu (The Movement Disorder Society's Tremor Investigation Group), esansiyel tremoru el titreme için başka bir açıklamanın olmadığı, başlıca ellerde ve kollarda iki taraflı, büyük ölçüde simetrik postural ya da kinetik titreme olarak tanımlamaktadır (6). Artmış katekolamin düzeyleri, stres, yorgunluk, santral sinir sistemini uyaran ilaçlar ve istemli hareketler titremelerin şiddetini artırırken, istirahat, $\beta$-blokerler, primidon ve alkolün tremorun şiddetini azalttığı gösterilmiştir (7).

ET'de tremor dışındaki nörolojik muayene bulguları normaldir. Hastalığın tanısı bazen tesadüfen ya da etkilenen kişinin işlevselliğinin olumsuz etkilenmesi nedeniyle başvurusu üzerine konur. Ellerin motor kontrolünün etkilenmesi nedeniyle birey yeme, içme, yazma gibi günlük aktivitelerinde ciddi sıkıntı yaşayabilir. Yaklaşık her üç ET'li olgudan ikisinin günlük yaşam aktivitelerinde önemli bozulmaların olduğu gösterilmiştir (8).

Tanısı öykü ve fizik muayene ile konulan ET'nin, tanıyı destekleyen özgül laboratuvar testi veya görüntüleme bulgusu yoktur. Yorgunluk, santral sinir sistemini uyaran ilaçlar, istemli hareketler ve stres esansiyel tremorun amplütüdünü artırırken, istirahat, $\beta$-blokerler, primidon ve alkol azaltmaktadır $(1,8)$.

ET'de motor belirtilere ek olarak bireyde bilişsel (kognitif) değişikliklerin ve psikiyatrik semptomların gözlenebilmektedir $(9,10)$. Günlük yaşam aktivitelerini engelleyecek şiddette titremesi olan hastaların tedavi edilmesi önerilmektedir. Kesin bir tedavisi olmayan ET'de ağır bileklik ve su içerken ağır bardak kullanma gibi yöntemler tremorun azaltılmasına katkı sunabilir. Illaç tedavisi hastaların \%50'sinde tremorda kısmen bir azalma sağlar ve maalesef \%30-50 hastada etkisizdir. Illk tercih edilen ilaç beta-adrenerjik blokerler (en sık propranolol)'dir (7).

Bu çalışmada çocuk nörolojisi polikliniğine başvuran ve esansiyel tremor tanısı konuşma olguların demografik, klinik ve tedavi özellikleri geriye dönük analiz edildi.

\section{GEREÇ ve YöNTEMLER}

Çocuk nörolojisi bölümüne Haziran 2016 - Haziran 2019 yılları arasındaki toplam üç yıllık süre içinde başlıca ellerde titreme yakınması ile başvuran olgulardan esansiyel tremor tanısı konulmuş olanların dosyaları geriye dönük analiz edildi. Olguların EEG, Kranial MR, Kranial Diffüzyon MRI sonuçları ve rutin biyokimyasal parametreleri incelendi.

Çalışmaya kabul edilme ölçütleri: iki taraflı el ve önkolların bilateral titremesi ve diğer nörolojik bulguların olmaması iken, Çalışmadan dışlama ölçütleri: Titreme dışında anormal nörolojik muayene varlığı, ailede veya kişide tiroid disfonksiyonu varlığı, psikomotor veya motor gelişimsel gecikmenin varlığı, titremeye neden olabilecek ilaçlar almak, ağır metaller, bizmut, civa, metilbromid tarafından zehirlenme, titremenin şiddetli görünümü, psikojenik kökenli titreme, ailesel tremor varlığı, anormal MRı bulgusu varlığı olarak belirlendi.

İstatistiksel Analizler: Analizlerde SPSS 17.0 (Chicago Inc., 2008) programı kullanıldı. Kategorik değişkenler sıklık (n) ve yüzde (\%) cinsinden ifade edildi. Sürekli değişken olan yaş (yıl) ortanca, minimum ve maksimum değerler cinsinden ifade edildi. Kategorik değişkenler için Pearson- $\chi^{2}$ ve Fisher's exact testleri kullanıldı. p<.05 anlamlılık düzeyi olarak kabul edildi.

Çalışma için Ankara Eğitim ve Araştırma Hastanesi, Klinik Araştırmalar Etik Kurulu'ndan 21.04.2020-245 karar numarası ile onay alınmıştır.

\section{BULGULAR}

İki yıllık süre içinde esansiyel tremor tanılı olguların toplam 93 olduğu, yaș ortanca değerinin 16 yll (6-18 yaş) olduğu, \% 54.8'inin ( $n=51$ ) kız ve \%4 5.2'sinin $(n=42)$ erkek olduğu saptandı. 


\begin{tabular}{|c|c|}
\hline & n (\%) \\
\hline Yaș (yıl)a & $16(6-18)$ \\
\hline $\begin{array}{l}\text { Yaş grup }{ }^{\dagger} \\
\text { Çocuk (6-11 yaş) } \\
\text { Ergen (12-18 yaș) }\end{array}$ & $\begin{array}{c}7(7.5) \\
86(92.5)\end{array}$ \\
\hline $\begin{array}{l}\text { Cinsiyet }{ }^{\dagger} \\
\text { KIz } \\
\text { Erkek }\end{array}$ & $\begin{array}{l}51(54.8) \\
42(45.2)\end{array}$ \\
\hline
\end{tabular}

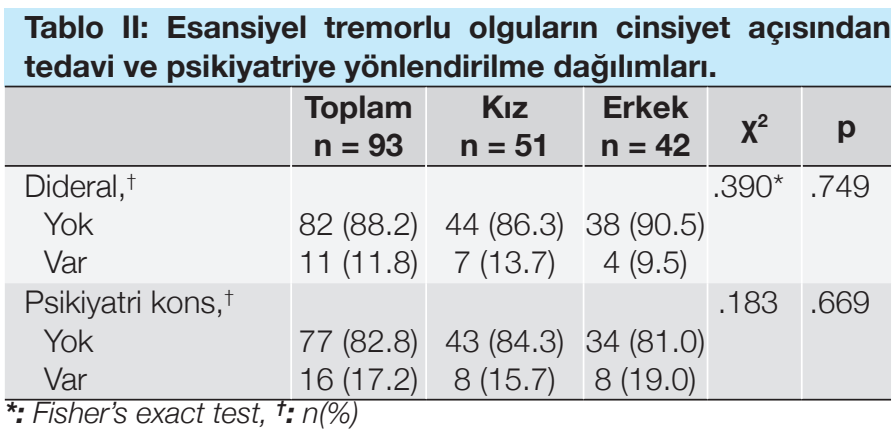

\begin{tabular}{|c|c|c|c|c|c|}
\hline & $\begin{array}{c}\text { Toplam } \\
n=93\end{array}$ & $\begin{array}{c}\text { Çocuk } \\
n=7\end{array}$ & $\begin{array}{l}\text { Ergen } \\
\mathrm{n}=86\end{array}$ & $x^{2}$ & p \\
\hline $\begin{array}{l}\text { Dideral }^{\dagger} \\
\text { Yok } \\
\text { Var }\end{array}$ & $\begin{array}{l}82(88.2) \\
11(11.8)\end{array}$ & $\begin{array}{c}7(100.0) \\
0\end{array}$ & $\begin{array}{c}0 \\
11(12.8)\end{array}$ & $1.015^{\star}$ & .593 \\
\hline $\begin{array}{l}\text { Psikiyatri kons }{ }^{\dagger} \\
\text { Yok } \\
\text { Var }\end{array}$ & $\begin{array}{l}77 \text { (82.8) } \\
16(17.2)\end{array}$ & $\begin{array}{l}5(71.4) \\
2(28.6)\end{array}$ & $\begin{array}{l}72(83.7) \\
14(16.3)\end{array}$ & $.687^{\star}$ & .346 \\
\hline
\end{tabular}

*: Fisher's exact test, ${ }^{\text {: }}$ n(\%)

Olguların \%7.5'i ( $n=7$ ) çocuk yaş grubunda (6-11 yaş) iken \%92.5'i ( $n=86$ ) ergen yaş grubunda (12-18 yaş)'tı. Çocuk/ Ergen oranı: 1/12.1 bulundu.

Olguların \%17.2'sinde $(n=16)$ esansiyel tremora sekonder gelişen psikiyatrik semptomlar nedeniyle çocuk-ergen psikiyatrisine danışılığı saptandı. Olguların \%11.8'ine ( $n=11)$ dideral tedavisi önerildiği gözlendi (Tablo I).

Esansiyel tremor olgularının cinsiyet açısından ilaç kullanımı ve psikiyatri bölümüne yönlendirilmesi değişkenleri ile arasındaki ilişki analiz edildiğinde, kız olguların \%11.8'ine $(n=11)$ ve erkek olguların \%9.5'ine $(n=4)$ propranolol ilacı önerildiği saptandı (p>.05) (Tablo II).

Esansiyel tremor olgularının yaş grupları açısından ilaç kullanımı ve psikiyatri bölümüne yönlendirilmesi değişkenleri ile arasındaki ilişki analiz edildiğinde, çocuk olguların \%15.7'sinden ( $n=8)$ ve erkek olguların \%9.5'ine $(n=4)$ propranolol ilacı önerildiği saptandı ( $p>$.05) (Tablo III).

\section{TARTIŞMA}

Esansiyel tremor (ET), tremorun en yaygın şeklidir ve muhtemelen tek bir hastalık varlığı yerine klinik bir sendromla karakterize edilen en yaygın hareket bozukluğudur.

Çalışmamıza ait kesitteki ET varlığı kIz ve erkek cinsiyetinde birbirine benzer oranlarda bulundu. Literatürde cinsiyetin benzer oranda etkilendiğini söyleyen çalısmalar $(3,11)$ daha ağır basmakla birlikte, çalışmaların yaklaşık üçte birinde ET'nin erkek cinsiyetinde daha sık görülme eğiliminde olduğu bildirilmektedir $(12,13)$. Uzunlamasına çalışmalarda ET'li kadın cinsiyetinde kafa tremorunun daha sık olduğu da bildirilmiş ve bu durumun açıklanması için ileri çalışmalara gereksinime işaret edilmiştir (13). Bizim geriye dönük kesitimizde böyle bir ayırım saptanmamıștır.

Çalışmamızda ergen yaş grubunda ET varlığının 12 kat daha fazla olduğu gözlendi. Esansiyel tremorun yaşın artmasıly birlikte arttığı literatürde çok çalışmada tutarlı bir şekilde vurgulanmıştır $(3,14,15)$. Yaşın ilerlemesi ile birlikte ET'nin şiddetinde artış ve başın tremoru gibi bulguların eklendiğini bildiren epidemiyolojik çalışmalar mevcuttur (15).

Esansiyel tremor olgularında sadece hareket bozukluğuna ilişkin semptomlar değil aynı zamanda bilişsel değişiklikler ve psikiyatrik semptom ve bulguların eklenebildiği, anksiyete ve depresyon semptomlarının kliniğe en sık eşlik eden psikiyatrik durumlar olduğu gösterilmiştir $(9,16)$. Sengul ve ark. (17) ET'li gençlerde bilişsel işlevlerde bozulmanın olduğunu, depresyon, anksiyete semptomlarında artış bulunduğunu, uyku kalitesinin düştüğünü göstermişlerdir. Psikiyatrik değerlendirme açııından kesitimize bakıldığında, hem kız-erkek cinsiyetlerinde, hem de çocuk-ergen yaş gruplarında benzer oranlarda psikiyatrik konsültasyon gereksinimi olduğu gözlenmiştir.

Hastanın, hastanın yaşamında neden olduğu bozulmaya ve bozulmaya ilişkin öznel deneyimi, hastanın klinik ziyareti sırasında objektif değerlendirmeden daha önemlidir. Bu tür bir değerlendirme zor olabilir. Çalışmalar, temel tremor hastalarında fiziksel insanın zihinsel yaşam kalitesi ölçümlerinin ortalama olarak sağl|klı bireylere göre daha düşük olduğunu göstermiştir (17).

Bireyin günlük işlevselliğini olumsuz etkilediği durumlarda ET'ye yönelik tedavi seçenekleri düşünülebilir. Uygulanan tedaviler semptomatik düzeyde etkili olup küratif nitelikte değildir. ET'li olguların yaklaşık \%50'sinde tremorda kısmen bir azalma sağlayan bu ilaçların, maalesef olguların \%30 ila 50'sinde etkisiz olduğu konusunda olgular iyice bilgilendirilmelidir (18).

Bugüne kadar ET tedavisinde kullanılan ilaçlar örneğin hipertansiyon gibi başka bir hastalığın tedavisi için uygulanırken ET'de de etkili olduğu şans eseri fark edilen ilaçlardır. $\beta$-blokerler ilk seçenek olup en sık kullanılanı propanololdür. Dirençli tremorlu olgularda cerrahi tedavi bir seçenek olup bu amaçla talamotomi 
veya talamusun derin beyin stimulasyonu ile uyarılması teknikleri uygulanmaktadır (18).

Propranolol, bir non-selektif beta adrenerjik reseptör antagonisti olup Amerikan Yemek ve İlaç Birliği (FDA) tarafından ET tedavisi için onaylanan tek ilaçtır. Oral yolla, günde 2 kez 40 mg'a kadar uygulanabilmektedir. Kabaca her üç ET'li olgunun biri propanolol tedavisine cevapsızdır (4). Bizim kesitimizde ilaç başlama oranı \%11.8 olup tümüne propranolol uygulanmıştır.

Atenolol, metoprolol, verapamil ve klonidin gibi diğer antihipertansif tedavi seçeneklerinin plaseboya göre ET belirtilerinde azalmaya neden olduğu ortaya konulmuş olsa da bu konuyla ilgili çalışmalar sınırlı sayıdadır ve daha geniş sayılı ve kontrollü çalışmalara intiyaç vardır (18). Bizim kesitimizde propranolol dişında uygulanan başka bir ilaç seçeneği olmamıştır.

Çalışmamızın kısıtıııkları: Geriye dönük bir analizdir. Tremorun şiddeti değerlendirilememiştir. Kesitsel nitelikte olduğu için sonuçlar genellenemez. Bununla birlikte yaşla arttığı, kızerkek cinsiyetin benzer oranda ET sergilediği ve benzer oranda psikiyatri desteğine gereksinim duyduğu bulgularımız, literatür ile uyumludur.

Sonuç olarak, Esansiyel tremorlu olguların yaş ve cinsiyetten bağımsız psikiyatrik semptomlar göstermesi, böylesi olguların psikiyatri bölümüne danışılmasının gerekliliğine işaret edebilir.

\section{KAYNAKLAR}

1. Kızıltan G. Çocuk ve ergende nörolojik hastalıklara yaklaşım rehber kitabı 2015. 163. Chapter. Tremor ve Ilişkili Durumlar. İstanbul Üniversitesi, Cerrahpaşa Tıp Fakültesi, Nöroloji AD. Türk Nöroloji Derneği Kitabı 163-9.

2. Keller S, Dure LS. Tremor in childhood. Semin Pediatr Neurol 2009; 16: $60-70$.

3. Meoni S, Macerollo A, Moro E. Sex differences in movement disorders. Nat Rev Neurol 2020;16:84-96.

4. Sullivan KL, Hauser RA, Zesiewicz TA. Essential Tremor Epidemiology, Diagnosis, and Treatment. The Neurologist 2004; 10:250-8.

5. Charles PD, Esper GJ, Davis TL, Maciunas RJ, Robertson D. Classification of Tremor and Update on Treatment. Am Fam Physician 1999; 59:1565-72.

6. Deuschl G, Bain P, Brin M. Consensus statement of the Movement Disorder Society on Tremor. Ad Hoc Scientific Committee. Mov Disord 1998; 13 Suppl 3: 2-23.

7. Tüzün S, Çiftçili S, Apaydın-Kaya Ç. Tremor I: Tanı ve tedavi. Türk Aile Hek Derg 2009; 13:200-5.

8. Louis ED. Essential tremor. Lancet Neurol 2005;4:100-10.

9. Acar BA, Acar T. Esansiyel Tremor Sadece Hareket Hastalığı Değildir; Uyku ve Anksiyetenin Hastalıkla Ilişkisi. Nöropsikiyatri Arşivi 2019;56:18-22.

10. Chandran V, Pal PK, Reddy JYC, Thennarasu K, Yadav R, Shivashankar N. Non-motor features in essential tremor. Acta Neurol Scand 2012;125: 332-7.
11. Hubble JP, Busenbark KL, Pahwa R, Lyons K, Koller WC. Clinical expression of essential tremor: Effects of gender and age. Movement Disorder 1997;12: 969-72.

12. Louis ED, Ferreira JJ. How common is the most common adult movement disorder? Update on the worldwide prevalence of essential tremor. Mov Disord 2010; 25: 53441.

13. Hardesty DE, Maraganore DM, Matsumoto JY, Louis ED. Increased risk of headtremor in women with essential tremor: longitudinal data from the Rochester Epidemiology Project. Mov Disord 2004;19:529-33.

14. Louis ED. Essential tremor: a nuanced approach to the clinical features. Pract Neurol 2019;19:389-98.

15. 15.Louis ED. The Roles of Age and Aging in Essential Tremor: An Epidemiological Perspective. Neuroepidemiology. 2019;52(12):111-8.

16. Yaşar H, Balıbey H, Tekeli H, Alay S, Şenol MG, Türker T, Bayar N. Genç Erkek Esansiyel Tremor Hastalarında Anksiyete ve Depresyon Düzeyleri. Journal of Mood Disorders 2014; 4: 66-9.

17. Sengul Y, Sengul HS, Yucekaya SK, Yucel S, Bakim B, Pazarci NK, et al. Cognitive functions, fatigue, depression, anxiety and sleep disturbances: assesment of nonmotor features in young patients with essential tremor. Acta Neurol Belg 2015; 115: 281-7.

18. 18.Zesiewicz TA, Chari A, Jahan I, Miller AM, Sullivan KL. Overview of essential tremor. Neuropsychiatr Dis Treat 2010; 6:401-8. 